\title{
Yaratıcı Drama Sürecinde Yaratıcı Yazma
}

\author{
Müjdat ATAMAN* \\ Bilkent Üniversitesi
}

\begin{abstract}
Özet
Bu çalışma, yaratıcı drama uygulamalan ile yazınsal değeri olan ürünler ortaya çlkarmak ve ögrencilerde yazmaya karşt istek uyandırmak amactyla yapılmışttr: Çalışma, Bilkent Üniversitesi Hazırlık Okulu 4. sınıf öğrencileri ile yürütülmiişstür: Çalışma tek bir sözcïkten (bavul), yola çıklarak kurgulanmıs ve yazılı anlatım çalısmalar bu sözcük etrafinda şekillendirilmiştir: Yazıll anlatım çalısmalarn öncesi, yaratıcı drama uygulamalar yapllarak, ögrencilerin, yazacaklartm dïşlemeleri, oynamalan ve canlandımaları sağlanmıştı: Bu çalışmada yaratıcı drama, yöntem olarak kullanlmıştı: Yazım öncesi yaratıcı drama uygulamalarında, şiir; öykü ve masallardan yararlantmışttr: Her atölye sonrast, ögrenciler yazinsal değeri olan ürünler ortaya koymuşlardır: Yaratıcl drama yöntem olarak kullantlı̆̆ında. Türkçe dersinin yazma kazanmları verilirken etkili olduğu, yazınsal değeri olan ürünler ortaya çıkmasında yarar sağladığı, ögrencilerin yazıll anlatım çalışmalartna istekle katıldiğı somucuna varllmıstır.
\end{abstract}

Anahtar sözcükler: Yaratıclllk, yaratıct drama, yaratıcı yazma, yazll ürün

\begin{abstract}
This study is aimed at creating written products of literary value. It is also aimed at motivating students to write high quality products. The study was carried out with fourth grade students from Bilkent University Preparatory School. In this activity students are given one word, which in this case was "suitcase". All subsequemt written activities involved this word as the central idea. Students used a variety of drama practices in class, afterwards they were given a written assignment that was linked to the drama lesson that they had just completed. Creative drama was used as a prewriting activity including the acting out of poems, histories, and tales. The students developed products of literary value after every workshop. The study suggests that when creative drama is used as a method for prewriting, students are enthusiastic about writing and are able to create written product of high quality.
\end{abstract}

Keywords: Creativity, creative drama, creative writing, written product

*Bilkent Üniversitesi Hazılık Okuh, Stmt Ögretmeni, E-posta: mujdatataman@yahoo.com 


\section{Giriş}

Bilim ve teknoloji çağı olarak adlandırılan günümüzde yaşanan bilgi patlaması, bilimsel ve teknolojik alanda kaydedilen hızlı gelişme ve değişmeler ekonomik, sosyal ve siyasal alanda da birçok gelişmelere sebep olmaktadır. Bu durum hem insanları hem de toplumları etkilemekte, bunun sonucunda yeni yaşam biçimleri ortaya çımaktadır (Akkoyunlu, 1994). Ancak, endüstrileşme ya da bilgi toplumu olmak salt ekonomik ve teknik olguların benimsenmesi anlamma gelmemektedir. Asıl olan çağın gerektirdiği yeni düşünme biçimlerine ulaşmak, her alanda üretken, yaratıcı olmak ve yaratıcı bireyleri yetiştirmektir (San, 1996).

Türkiye'deki okullar halen otoriter, daha çok zihinsel gelişmeye önem veren, sosyal gelişmeyi ihmal eden, sosyal faaliyetleri kısıtlayan, öğrencilerin yaratıcılıklarını törpüleyen kurumlar olarak eleştirilmektedir (Tezcan, 1987).

Yazı yazma, çocuklar tarafindan genellikle hoşa giden bir etkinlik olarak görülmez. Bunun nedenleri arasında, yazı yazarken çoğu kez sıkı kurallara bağlı kalmak zorunluluğu vardır. Kağıt temizliği, harflerin nasıl çizilmesi gerektiği, yazının düzgün olması ve dil bilgisi hakkındaki kuralların okulun ilk yıllarında ağırlıklı olarak ögretilmesi, çocukların bir taraftan yazım tekniğini öğrenmelerini sağlarken diğer taraftan yazı yazmaktan nefret etmelerine yol açabilmektedir. $\mathrm{Bu}$ tür etkinlikler, çocukların dikkatlerini yazının içeriğinden çok şekle yöneltir (Onar, 2003).

Yaratıcılık, daha önceden kurulmamış ilişkiler arasında ilișkiler kurabilme, böylece yeni bir düşünce şeması içinde yeni yaşantı, deneyim, fikir ve ürünler ortaya koyabilme ya da anlam evrenimizi yeniden yapılandırma, bireyler için ya da kültür için gerçekliğe uygun bir yenilik katmaktır. Yaratıcı olabilmek için her şeyden önce kişinin kendine güven duyması, çalışacağı alan hakkında temel bilgilere sahip olması, bağımsızca düşünebilmesi kimi zaman alışılmış kalıpları ve kuralları kırabilmesi, yeti ve yeteneklerini sonuna dek kullanabilme ortam ve özgürlüğünün kendisine sağlanmış olması gerekmektedir (San, 1985).

Yaratıcı insan, dışarıdaki şartlar ne kadar zorlayıcı olsa da aslında kendi iç dünyasının ne kadar özgür ve sınırsız olduğunu keşfetmiştir. Ayrıca, yaratıcılı̆gı içerdeki özgürlükle bağdaştırırken dikkat edilmesi gereken bir nokta vardır. Herkes yaratıcılık potansiyeline sahiptir. Bu potansiyel, kişiden kişiye şekil ve miktar değiştirir. Bazılarında daha az bazılarında daha çoktur; bazılarının yaratıcılığı sanat alanlarında çıkar, diğerlerinki bilim, felsefe ya da sporda kendini gösterir. Önemli olan, her insanın içinde az ya da çok miktarda yaratıcı potansiyelin olduğunu bilmektir. Bu potansiyel sahibi tarafindan keşfedilip, değerlendirilmeyi bekler. Yaratıcılık uyandırıldığında gerçek üretim süreci de başlar (Onar, 2003).

Yaratıcı drama, doğaçlama, rol oynama vb. tiyatro ya da drama tekniklerinden yararlanılarak, bir grup çalışması içinde, bireylerin bir yaşantıyı, bir olayı, bir fikri, kimi zaman bir soyut kavramı ya da bir davranışı, eski bilişsel örüntülerin yeniden düzenlenmesi yoluyla ve gözlem, deneyim, duygu ve yaşantıların gözden geçirildiği "oyunsu" süreçlerde anlamlandırılması, canlandırılmasıdır (San, 2002).

Yakınsak eğitim sistemi yerine iraksak düşünmeyi destekleyen, bireylerin yanlıs yapmaktan korkmadikları, araştırma, gözlem, duyu ve duyguların ön planda olduğu, bireyi ve yaratıcılığı merkeze alan çağdaş bir eğitim sistemine gereksinim duyulmaktadır. Bu sistemlerin uygulanabilir olması için de bu sisteme uygun çeşitli yöntem ve tekniklerin ögretmenler tarafından uygulanması gerekmektedir. Bu noktada öğrenciyi merkeze alan, öğrencinin yaratıcılığına izin veren bir yöntem ve disiplin olan yaratıcı dramanın önemi ortaya çıkmaktadır (Adıgüzel, 2003).

İpşiroğlu (1997), yaptığı araştırmalarda, yaratıcılığı geliştirici seminerlerde çalışan öğrencilerin, klasik öğrenim görenlere oranla çok daha ilgili ve başarılı olduklarını gördüklerini söylemekte, klasik öğrenimde öğrenciler özüm- 
seyemedikleri bilgileri ezber yoluyla öğrenirken, yaratıcı eğitimde düş gücünü geliştirmeyi ve düşünmeyi, başka deyişle öğrenmenin yöntemlerini öğreniyorlar, bu çalışmalarımız da bize öğrenimin nasıl olması gerektiğinin ipuçlarını veriyor demektedir.

Yaratıcı drama yoluyla dil ve düşünce geliştirilebilir. Motifett'in, dramatik etkileşimlerin, düşünme ve dil gelişiminin ilk aracı olduğuna inanan görüşleri Wagner tarafından yapılan bir araştırmada bulunan sonuçlarla desteklenmiştir. Wagner, yaratıcı dramanın öğrenme üzerindeki etkilerini araştırarak dramanın dil gelişimi yanı sıra kendine güven, benlik kavramı, kendini gerçekleştirme, empati, yardımseverlik ve işbirliği gibi bilişsel ve duyuşsal özelliklerin kazanılmasinda olumlu bir etkiye sahip olduğunu saptamıştır (Üstündağ, 1995).

Stabler, bir araştırması sonucunda eğitimde drama çalışmalarında değerlerden biri olan dilin gelişimi ile ilgili hedefleri şu şekilde belirtmiştir:

1. Konuşmada kendine güvenin gelişmesi,

2. Akıcılıkta gelişme,

3. Konuşma becerisinde gelişme,

4. Sözcük bilgisinde gelişme,

5. Duygu ve düşüncelerin ifadesi ve gelişimi,
6. İnsanlarla iletişim kurabilme becerisinde gelişme,

7. Dinleme becerisinin kazanılması,

8. Farklı durumlarda farklı dilin kullanılmasında gelişme,

9. Tartışma, ayırt etme ve değerlendirme becerisi

(Nixon, 1987, Akt.: Adtgüzel, 1993).

Yazma, düşünceyi kalıcı kılma, sözü çevrenin sinırları dışına taşıma demektir. Düşünce ve duygu alışverişini kolaylaştır. Yazı, insanlığın belleğidir aynı zamanda. Çağlar arasındaki düşünsel etkileşim büyük ölçüde yazının yardımıyla gerçekleşmiştir. Okuma ve yazma arasında da dinleme ve konuşma arasında olduğu gibi işlevsel bir benzerlik vardır (Özdemir, 1994).

Yazılı anlatım, bireyin kendi gördüğünü, duyduğunu, düşündüğünü ve yaşadığını yazarak anlatmasıdır. Çocuğun duygu ve düşüncelerini ifade etme şekli olan yazmanın gerçekleşmesi için çocuğun kendi yaşantısından yola çıkmak gerekmektedir (Kavcar, Oğuzkan ve Sever, 1995). Yazma becerisini mekanik bir süreç olarak değil eleştirel bir düşünme süreci olarak algılamak ve bilmek gerekmektedir (Demirel, 1996).

\section{Tablo 1}

Teknik Yazma ve Yaratıcı Yazma Arasindaki Farklıllklar

\begin{tabular}{lll}
\hline & Teknik Yazma & Yaratıcı Yazma \\
\hline IÇERIK & Gerçeğe dayanan, açık & Yaratıcı, mecazi veya sembolik \\
DiNLEYiCi, SEYİCi & Özgül & Genel \\
AMAÇ & Bilgi vermek, eğitmek, ikna etmek & Eğlendirmek, kışkırtmak, cezbetmek \\
TARZ & Resmi, standart, akademik & Resmi olmayan, sanatsal, mecazi \\
TAVIR & Objektif & Subjektif \\
SÖZ DAĞARCıĞı & Spesifik & Genel, çağrışım yapan \\
DÜZEN & Ardışık, sistematik & Keyfi, sanatsal \\
\hline
\end{tabular}

http://www.micron.com/k12/writing/differences.html 
Yaratıcı yazma,

- Dili yaşamak,

- Organizasyon yeteneklerini geliştirmek,

- Bilgiyi keşfetmek,

- Hayal gücünü genişletmek,

- Diğerleri ile paylaşmak,

- Tanımlayıcı dili kullanmak,

- Eleştirel analiz yeteneklerini kullanmak,

- Yaratıcı çalışmada zevk ve öz saygı bulmak,

- Temel gramer ve noktalama yeteneklerini kullanmak,

- Yazmada becerikli ve emin olmak,

- Kendini açıkça anlatmayı öğrenmek için işe koşulabilir.

(www.teachertoo.com/whycreativewriting.html)

Rensenbrink (1987), çocukların yazma için kendi doğal heveslerini korumalarına yardım edecek çeşitli aktiviteler önerir. Çoğu çocuk için kurgusal yazmanın en eğlenceli yanlarından biri de kendi hikayelerine davet edebilecekleri çeşitli karakterlerde görünmez arkadaşlar yaratmalarıdır. Bununla birlikte, bu ilişkiye yabancı olan okuyucuda bu karakterler düz ve tek boyutlu, daha doğrusu gerçekçi olmayan izlenimini yaratabilir.

Yaratıcı dramada öykülerden, şiirlerden ve masallardan pek çok biçimde yararlanılabilir. Bunların bir bölümü var olan öyküler üzerinde çalışmaktır. Bir bölümü de yeni öyküler yaratmak olabilir. Var olan öyküleri başlangıcını, ortasını ve sonunu değiştirmek ve bilinen öyküleri bir araya getirip yeni öyküler yazmak bu çalışmalar arasında yer alabilir. Yaratıcı dramada şiir, oynama ya da oluşturma çalışmaları bireyin imgelem gücünü geliştirmedeki önemli anahtarlardan biridir. $\mathrm{Bu}$ anahtarla birey düş gücünü de harekete geçirir. Yaratıcı dramada masala ilişkin çalışmalar, yazınsal türlerden yola çıkarak yaratıcı düşünceyi geliştirmek adına yapılan önemli çalışmalar arasındadır. Şiir ve öykü içinde sıralanan, söz dağarcığını geliştirme ve düş gücünü harekete geçirme vd. işlevleri de yerine getirirler (Üstündağ, 2001).
Dil sanatı, dinlemekten, konuşmaktan, okumaktan ve yazmaktan oluşur. Bu maddelerden hiçbiri tek başına olamaz. Yazmayı öğretirken bunun iletişimin bir formu olduğunu hatırlamak gerekir. Yazmak başlı başına bir süreçtir. Yaratıcı drama yoluyla ögretilebilen yaratıcı yazma bu iletişimin dört formunu yaratıcı ve bütüncül bir yolla etkileştirebilen bir araçtır. Yaratıcı drama sınıf metodolojisinin bir parçası haline getirildiğinde öğrenciler hayal güçlerini ve yaratıcılıklarını kullanarak öğrenme sürecinin bir parçası olarak bütün bir şekilde sürece katılırlar (Annarella, 1999).

Yazma süreci beyin firtınası, yazma, ekleme, tekrar yazma, yayınlama gibi işlemleri de kapsadığı için yaratıcı drama teknikleri yazma süreci kapsamlarının gelişmesine yardımcı olabilir. Yazma süreci kullanılarak yazma öğretildiğinde ögrencilerin yazdıklarının kalitesinde çok tatmin edici bir fark olduğu gözlenmiştir (Annarella, 1999).

$\mathrm{Bu}$ çalışmada da öğrencilerle çeşitli yaratıcı drama uygulamalarından sonra yazınsal çalışmalar yapılmış ve öğrencilerin ürünlerinin oldukça yaratıcı olduğu ve ögrencilerin bu süreçten zevk aldığı görülmüştür.

\section{Araştırma Yöntemi ve Araçlart}

$\mathrm{Bu}$ çalışmada, yaratıcı drama uygulamaları ile yazınsal değeri olan ürünler ortaya çıkarmak ve öğrencilerde yazmaya karşı istek uyandırmak projenin genel amacını oluşturmaktadır.

Çalışma konusu olarak "bavul” sözcüğünden yola çıkılmıştır. "Bavul" sözcügüünün seçilmesinin nedeni, sözcügün somut bir nesne olması ve tüm öğrenciler için bir anlam ifade etmesidir. Bir nesne olarak bavul, yaşamımızın mutlaka bir anında yer almaktadır. Tüm öğrencilerin bu nesne ile ilgili bir yaşantılarının olduğu öngörülmüştür. "Bavul" sözcüğünün birçok çağrışıma yol açacağı varsayılarak projeye başlanmıştır.

Çalışmaya 14 öğrenci (10 kız, 4 erkek - 9 ve 10 yaş grubu) katılmıştır. Katılımcılar, Bilkent Üniversitesi Hazırlık Okulu 4. sinıfta okuyan 
öğrencilerdir. Katılımcılar dördüncü sınıfa kadar, ikinci sinıftan itibaren iki haftada bir ders saatlik (40 dakika) Yaratıcı Drama dersleri almışlardır.

Her oturum, $14.45-16.00$ saatleri arasinda 75'er dakika olup, çalışma 21.09.2004 9.11.2004 tarihleri arasında toplam yedi oturum olarak gerçekleştirilmiştir.

Calışmanın yapıldığı mekan, yerleşke içinde spor derslerinin ve yaratıcı drama derslerinin yapıldığı farklı bir binadır. Çalışma için kullanılan bölüm $15 \times 8=120$ metrekarelik bir alandır.

Yaratıcı drama uygulama aşamaları;

\section{1- Hazırlik- Isinma \\ 2- Canlandirma \\ 3- Değerlendirme}

olarak uygulanmıştır (Adıgüzel, 2002).

\section{Bulgular}

Birinci haftanın temel kazanımı, çağrışım sözcükleriyle dörtlükler oluşturmaktı. Öğrenciler, heykel çalışmasında sözcükler üretip, bu sözcükleri kullanarak, şiirler yazdılar. Çalışmanın sonunda gruba verilen değerlendirme formunda yetmiş farklı duygu durumu yer alıyordu. Öğrencilerden bu çalışmayı yaparken hissettikleri en yoğun duyguyu formlardaki yüzleri boyayarak göstermeleri istendi. On dört ögrencinin, 4'ü (\%28.5) endişeli, 4'ü (\%28.5) heyecanlı, 2'si (\%14.3) neșeli, 2'si ( \%14.3) mutlu, 1'i (\%7.2) ümitsiz, l'i ( \%7.2) sıkılmış duyguyu belirttiler.

İkinci haftanın temel kazanımında öğrencilerden, çağrışım yoluyla bulunan sözcükleri kullanarak öyküleyici anlatım yapmaları beklendi. Öğrenciler, sergilenen 'fotoğraf anı' ile ilgili, canlandırma yapan grupların bedenlerine verdikleri biçimi göz önüne alarak, çağrışım sözcükler yazdılar. Gruptaki öğrencilere canlandırmalar öncesi oluşan sözcükler dağttıldı. Öğrenciler bu sözcükleri kullanarak başlığı "bavul" olan bir öykü yazdılar. Öğrencilerin; 7'si (\%50) öykü yazmak istediğini belirtti, 4'ü (\% 28.5) öykü yazma konusunda yorum yapmadı, 3'ü (\% 21.5) öykü yazmak istemediğini belirtti. Öğrenciler, çağrışım yoluyla bulunan sözcükleri kullanarak öyküleyici anlatım yaptılar.

Üçüncü hafta öğrencilerin, bir başlıktan yola çıkarak öykü yazmaları beklendi. Öğrencilerden çalışma sonrası bazı soruları yanıtlamaları istenmiştir. Öğrencilerin 10'u başlıktan yola çıkarak öykü yazmakta zorlanmadıklarını, aynı sayıda öğrenci de öykü yazmaya istek duyduklarını belirttiler.

Dördüncü haftada, yaratıcı drama sürecinde masallardan yararlanıldı. Yarım bırakılan ürünün, ögrenciler tarafından tamamlanması istendi. Öğrenciler bavul içinde bulunan nesnelerden istediklerini seçerek, bildikleri bir masalla ilgili canlandırma yaparken bu nesneleri kullandilar. Canlandırma aşamasında gruplar, "bavul"u da kullanarak dramaya geçiş yaptılar. Öğrenciler yarım bırakılarak verilen beş farklı masaldan (Pamuk Prenses, Güzel ve Çirkin, Uyuyan Güzel, Kül Kedisi, Rapunzel) birini seçtiler. Seçtikleri masalda, masal kurgusunu bozmadan "bavul"u da kullanarak masalı kendi hayal güçleriyle şekillendirerek sonlandirdılar.

Öğrenciler çalışmanın beşinci haftasında verilen fotoğraftan yola çıkarak öykü yazdılar. Öykü yazım çalışması sonunda, öğrenciler karikatürler çizerek çalışmayı değerlendirdiler. Karikatürler incelendiğinde, öğrencilerin çalışmaya istekle katıldıkları belirlendi.

Altıncı haftada, öğrencilerden sözlü öykü oluşturmaları, oluşan öyküyü canlandırmaları ve yazılı olarak anlatmaları beklendi. Verilen ilk tümceye, sirayla birer tümce ekleyerek bir gerilim öyküsü oluşturdular. Bu süreçte öğrenciler, kendilerinden önceki arkadaşlarını dikkatle dinleyip kurgudan, zamandan kopmayıp ortak üretimleri olan öykülerini tamamladılar. Oluşturulan sözlü öyküyü de göz önünde bulundurarak gruplar, oluşturdukları yeni öyküleri canlandırdılar. $\mathrm{Bu}$ canlandırmalar sonucunda öğrencilere ne tür bir öykü yazmak istedikleri sorulduğunda, öğrenci- 
lerin tamamı gerilim öyküsü yazmak istediklerini bildirdi. Süreç sonunda tüm öğrenciler gerilim öyküleri yazdi.

Çalışmanın son haftasında öğrencilerden, hayal güçlerini yaratıcı yazmada kullanmaları beklendi. Ögrenciler verilen fotoğraftan yola çıkarak betimleyici tümceler kurdular. Gruplar fotoğrafı kullanarak oluşturdukları kurguyu canlandırdılar. Canlandırmalar sonunda öğrenciler bireysel olarak hayal güçlerini zorlayıp bu fotoğrafla ilgili bir öykü yazdılar.

\section{Tartışma}

Türkiye'deki okullar halen otoriter, daha çok zihinsel gelişmeye önem veren, sosyal gelişmeyi ihmal eden, sosyal faaliyetleri kısıtlayan, öğrencilerin yaratıcılıklarını törpüleyen kurumlar olarak eleştirilmektedir (Tezcan, 1987).

Eğitim sistemimizde bilgi aktarım yöntemi ezber halinde verilmektedir. Bu koşullar altında bireyin çevresini ve içinde yaşadığı dünyayı algılaması ve anlaması güçleşmektedir. Öğrencileri, yaratıcılığa ve eleştirel düşünmeye yöneltecek olan yöntemlerin kullanılması önem kazanmaktadır. Bütün bu özellikleri bireye kazandırmanın yolu, klasik eğitim sistemimizden geçmemektedir. Günümüzde bireyden beklentilerin farklılaşması, bireyin yetiştirilmesinde etkili olan eğitim programlarına önemli sorumluluklar yüklemektedir (Floyd, 1965).

Yazma, duygu ve düşünceleri eyleme geçirme sürecidir. Genelde çocuklar ve yetişkinler zorunlu olmadikça yazma eyleminden uzak dururlar. Ilköğretim Türkçe programındaki yazma kazanımları, yazmayı zorunlu kılmasına rağmen yaratıcı yazmanın önünü açmamaktadır. 1968'den beri uygulanan ilkokul programı yazılı anlatım konusunda yetersiz kalmıştır. Yazma işi ise bir tür "külfet" olarak görülmüştür. Yazılı anlatım denildiğinde, okula ilişkin akla gelen ilk yazılı eylem bir atasözünü açıklamaktan ileri gitmez. Metin oluşturma çalışmaları yapılmadan, konu akışının nasıl verileceği belirlenmeden, çatışma anları ortaya konmadan yapılacak bir anlatımın sonucunda ortaya çıkacak ürünün, yazınsal değeri konusunda olumlu şeyler söylenemez. Yazılı anlatım çalışmalarında yapılandırıcı bir yöntem izlenmemekte, aynı süreç her sınıf seviyesinde tekrarlanmaktadır. İlkögretimin ikinci sınıfında verilen giriş, gelişme, sonuç gibi yazma kalıbı, on ikinci smıfa kadar devam etmekte, her yıl tekrarlanan bu yazma kalıbı da süreç içerisinde doğru işlememektedir. Öğrencilerin yazılı anlatımları, olması gereken noktadan çok daha geridedir. Ölçme yöntemlerimiz, son yıllarda özellikle yoğunlaşan sınav kaygısı nedeniyle tamamen sonuca yönelik olmaktadır. Sonuca yönelik ölçme sistemimizin neredeyse tamamını çoktan seçmeli sinav soruları oluşturmaktadır. $\mathrm{Bu}$ sistem ögrencileri yazmadan uzaklaştırmakta, sadece okuduğunu yorumlama becerisini geliştirmektedir. Bu sistemde yetişen öğrencilerin, yazmaktan sıkıldığı, yazarken zorlandığı ve konu örüntüsü oluşturmakta başarısız olduğu gözlenmektedir.

Bu çalışmada; öğrencilerin klasik yazma çalışmaları dışına çıkarak, yaratıcı drama sürecinde girdikleri kurgusal dünyadan da yararlanılarak, yaratıcı yazma çalışmaları yapılmıştır. Çalışmalarda öğrencilerden gelen ürünlerin, hedeflenen kazanımlara ulaştığı gözlenmiş ve öğrencilerin severek yazı yazdıkları belirlenmiştir.

Bu çalışma, yaratıcı yazma çalışmaları için sadece bir örnek teşkil etmektedir. Yaratıcı drama sürecinde yaratıcı yazmaya çok daha farklı şekillerde yer verilebilir.

\section{Sonuç ve Öneriler}

Çocuk, kendine özgü özellikleriyle yoğun bir düş gücüne sahiptir. Bu zengin düş gücü sayesinde bütün dünyayı kendi ayakları altına alır, dünyayı kendi etrafında görür; hiçbir nesnelliğe ve nedenselliğe bağlı kalmadan bu düş dünyasında olabildiğince özgür ve kendince yaşar. Cocuğun kendini en rahat ifade ettiği ya da gerçekleştirdiği alanlardan biri de oyundur. Oynarken izlediğimiz çoğu çocuk, kendi düşünde kurguladığı öznel dünyayı, nesnel dünyanın araçlarıyla özdeşleştirir (Dilidüzgün, 2002).

Eğitim sürecinde çocukları oyundan ayırma ya da uygulanan eğitim yöntem ve tekniklerinde 
oyunu yadsıma, okulların çocuklar için sıkıcı bir kimliğe bürünmesine neden olmaktadır.

Çoğu çocuk kendilerini kelimelerle ifade etmeye ihtiyaç duyan bir mirasla okula, yazmaya doğal bir ilgi duyarak başlar. Çocukların hikayelere ve çocuk şiirlerine olan sevgileri ile ögrenciler için yaratıcı yazmayı başlatan ve kapsayan temeller arasında bir bağ kurulmalıdır.

Oysa eğitim sistemimizde böyle bir bağ yerine öğrencileri, basmakalıp yazma düzenine sokmaya çalışan bir yapı söz konusudur. Ögrencilerle yapılan yazma çalışmaları öncesi, öğrencilerin düşünceleri alınmamakta ya da ne yazmak istedikleri sorulmamaktadır. Daha da önemlisi öğrencileri yazmaya motive edecek ya da onları yazmaya itecek neden yoktur. Oysa bu çalışmada yapılan drama etkinliklerinde, öğrencilerin oyun oynaması sağlanmıs, bu sayede öğrenciler isteyerek ve zevk alarak sürece katılmıştır. Ardından yapılan canlandırma aşamalarında öğrenciler, kurgusal yaşama geçiş sağlamış ve kurgusal yaşamdan çıktıklarında yazma için gerekli donanıma ve yazma isteğine hazır hale gelmişlerdir.

Yazma sürecini öğretmedeki en zor bölümlerden biri de öğrenciler için hakkında yazabilecekleri bir konu bulmak ya da onların konuyu keşfetmelerini sağlamaktır. Yazmak için ilgilerini çeken hiçbir şeyin olmadığını söyleyen, hiçbir şeyin değişmediğini ve sıkıldıklarını söyleyen öğrencilerin sayısı çoktur. Öğrencilerin düşündüklerini kelimelere dökmeleri zordur. Bunun için öğretmenler, hayal gücünü ortaya çlkarabilecek ve öğrencilerin yaratıcılıklarını harekete geçirecek yollar önerebilirler.

Eğer öğrencilere, onların hayal güçlerinin olduğunu keşfetmelerini sağlayıp, hayalleri hakkında konuştuklarını gösterebilirsek büyük olasılıkla onların yazmalarını da sağlayabiliriz. Bunu da sağlamanın en güzel yolu yaratıcı dramanın işe koşulmasıdır. Bu çalışmada yapılan yaratıcı drama uygulamaları ile tek bir kelimeden (bavul) yola çıkılmış, ögrencilerin bavulla ilgili yaşantıları harekete geçirilmiş, hayal kurmaları sağlanmıştır. Öğrenciler bu çalışmada bavulla ilgili çağrışım sözcükler yazıp, bu sözcükleri de kullanarak şiir ve öykü yazmışlardır. Öğrenciler kendi kurgusal dünyalarında yer alan maceracı ruhlarını, bavulla özdeşleştirip yazılı anlatımlarında, fantastik öyküler ortaya çıkarmışlardır. $\mathrm{Bu}$ çalışmada tek bir sözcük yedi hafta boyunca yazılı ürünlerde temel çıkış noktası olmuştur. $\mathrm{Bu}$ durum kimi zaman ögrencilerin sıkılmasına yol açsa bile, drama çalışmalarının ardından yazma çalışması yapılırken, ögrencilerin severek yazılı anlatım yaptıkları gözlemlenmiştir. Bu çalışma Türkçe dersinin yapısına ve konusuna uygun olarak farklılaştırılıp genişletilebilir.

Öğrenciler yaratıcı drama sürecinde canlandırma yaparken betimlemelere yer vermiş ve betimlemeleri yazılı ürünlere de yansımıştır. Öğrencilerden gelen yazılı ürünlerde yaş seviyesinin üstünde betimlemeler yapıldığı gözlemlenmiștir. Öğrenciler öykülerinde, gerekli olan öykü ögelerine (yer, zaman, vb.) ve çatışma anlarına yer vermişlerdir.

Bu çalışmada merak duygusunu hep ön planda tutan masallar da kullanılmıştır. Öğrenciler masallarla ilgili canlandırmalar yapmıs ve yazılı ürünlerinde bavulu da kullanarak merak duygusundan ayrılmadan, masallarını yeni kurgularla ortaya çıkarmışlardır.

$\mathrm{Bu}$ çalışmada ortaya çıkan yazınsal ürünler, yazarları olan ögrenciler tarafından arkadaşlarına okunarak onlarla paylaşılmıştır. Öğrencilerin birbirlerinin çalışmalarını okumaları ve yorum yapmaları hem yazıyı yazan ögrenciye, hem de yazıyı dinleyen öğrencilere yardım edebilir. Yazarlar, çalışmaları için dinleyici sağlayabilirler. Coğu çocuk için akranlarının yorumları, ögretmenlerinin yorumlarından daha çok dikkate alınabilir.

Yaratıcı yazma çalışmaları öğrencilerin, öğretmenlerinin diğer yönlerini de kullanmaya özendirecek, kritik düşünme yeteneklerinin ilerlemesini sağlayacaktır.

Çoğu öğretmen yaratıcı yazmayı "not verilmesi imkansız" olarak görür ve değerlendirmenin tüm hallerinin öznel ve sıklikla adaletsiz olduğunu düşünür. Bu inanışla ilgili olarak, eğer öğrencilerin çalışması adil olarak değerlendiril- 
mezse gelişme ve ilerlemesini açıkça izlemenin bir yolu olmayacağını düşünürler. Glazer (1994), bu endişeleri kabul eder, ama değerlendirmenin pratik, kullanışlı ve adil olabileceğini savunur. $\mathrm{Bu}$ değerlendirme, öğretmenlerin değerlendirecek tutarlı kriterleri açıç̧a bildirmelerini sağlar. İşin kalitesi için öğretmenin genel etkisine güvenmektense veya diğer öğrencilerin çalışmalarıyla karşılaştırmaktansa betimleme, düzen ve noktalama gibi yazma yetileri üzerine odaklanan kriterler olmalıdır. Bu kriterler, özel öğrenci güçlerine veya zayıflıklarına göre değiştirilebilir ve çocukların yeteneklerini geliştirmek için biraz daha değiştirilebilir. Bu çalışmada ögrencilerin yaratıcılığı önemsenmiş ve ortaya çıkan yazınsal ürünlerde yaratıcı düşünceler olduğu gözlemlenmiştir. Bu çalışmada her ne kadar not verilerek değerlendirme yapılmasa da öğretmenler yaratıcı yazma çalışmalarını da farklı kriterlerle değerlendirebilirler. Yine benzer bir uygulamada bu çalışma grubundan bir öğrencinin (Naz Akyol), yaratıcı drama süreci sonunda ortaya çıkan yaratıcı yazma çalışması, Garanti Bankası ve Türk Sinema Yazarları Birliğinin tüm Türkiye'de düzenlemiş olduğu, "Hayalimdeki Film Senaryosu" yarışmasında dereceye girmiş ve öyküsü bu yarışmada dereceye giren diğer ürünlerle beraber yarışma sonunda basılan kitapta yer almıştır.

Ülkemizde bu y1l (2005) ilköğretim programı konusunda köklü yenilikler yapılmıştır. Programın yapılandırıcı yaklaşımla düzenlenmesi sevindiricidir. Buna rağmen yeni programın da Türkçe kazanımları konusunda birçok eksikliği olduğu gözlemlenmektedir. Yeni programda, yaratıcı yazma çalışmaları ve hayal dünyasına yönelik yazma çalışmaları artırılmalıdır. Yazılı anlatımın nasıl değerlendirileceği yeterince açıklanmamıştır. Yazma ögretiminde yaratıcılık ön planda tutulmamış ve yazma kazanımlarında yapılandırıcı yaklaşım önemsenmemiştir. Yazmada ele alınan hazırlık bölümü olumlu olmasına rağmen, yazma çalışmalarında öğrencileri motive edecek kazanımlar bulunmamaktadır.

MEB'in, tüm Türkiye'de uygulayacağı programda tüm kazanımlarla beraber yazma kazanımları da eğitim-öğretim dönemi sonrası ele alınmalı, öğretmenlerden alman dönütler değerlendirilmeli ve bu değerlendirmeler ışığında kazanımlar yeniden, yapılandırıcı yaklaşıma göre düzenlenmelidir. Bu çalışmada ortaya çıkan geri bildirimlerden biri de, öğrencilerin ancak sevecekleri konuda yazmaya istekli olduklarıdır. MEB'in yazılı anlatım kazanımları, öğrencilerin kendi yaşamlarından yola çıkarak yazı yazabilecekleri şekilde düzenlenmeli, böylece öğrencilerin severek yazı yazmaları sağlanmalıdır.

Öğretmenlere yaratıcı drama alanı ve yaratıcı yazma çalışmaları tanıtılmalıdır. MEB, üniversitelerin ilgili birimleriyle bir araya gelip bir komisyon oluşturabilir. Bu komisyon hizmet içi seminerlerinde ögretmenlere, yaratıcı darama ve yaratıcı yazma çalışmalarını tanıtıcı sunumlar yapabilir.

Türkçe öğretmenleri ve sinıf öğretmenleri yazılı anlatım çalışmaları öncesi yaratıcı dramayı kullanarak, öğrencilerin yazılı anlatım yapacakları konuyu sınıf içinde canlandırmalarını, böylece öğrencilerin yazılı anlatım çalışmaları öncesi yazmaya istek duymalarını sağlayabilirler.

Yazılı anlatım çalışmaları sonunda, öğrencilerden gelen ürünler sadece öğretmen tarafından okunmamalı, bu ürünlerin değerli olduğu bilinmeli ve yazarları tarafindan okunarak, sınıfta diğer öğrencilerle paylaşılmalıdır.

Öğrencilerin yazılı anlatımlarındaki farklılık, onların bireysel farklılığı ile ilișkilendirilmeli ve tüm yazılı ürünler kendi içlerinde değerlendirilmelidir. Bu değerlendirme için, öz değerlendirme formlan (rubric) hazırlanabilir. Ögrenciler bu şekilde kendi kendilerini değerlendirmeyi öğrenebilirler. Ögrencilerden gelen düşüncelerin, onların hayal güçlerinin ürünü olduğu unutulmamalı ve hayal güçlerini kısıtlayıcı kurallar koymak yerine, öğrencilerin hayal güçlerini destekleyecek çalışmalara yer verilmelidir.

Yazılı anlatımın bir gelişim süreci olduğu unutulmamalı ve öğrencilerden gelen ilk ürünlerin yazınsal değeri olması beklenmemelidir. Yaratıcı yazma çalışmaları öncesi öğrencilerle kısa anlatım (sözlü ya da yazılı) çalışmaları yapılmall, somut nesnelerin betimlenmesi gibi basit uygulamalarla öğrenciler yazılı anlatım sürecine başlamalıdır. 
Yazınsal değeri olan ürünler ortaya çıkarmak için, öğrencilerin yazın değeri olan kitaplar, öyküler, şiirler okumaları sağlanmalıdır. Öğretmenler çocuk yazınını, çocuk yazını konusundaki yenilikleri izlemelidir. Yaratıcı yazma çalışmalarında öğretmenler, yazın değeri olan ürünleri kullanabilirler. Yine sanatsal değeri olan, seviyeye uygun fotoğraflar, resimler, filmler ve müzikler yazılı anlatım çalışmaları için kullanılabilir.

\section{Kaynaklar}

Adıgüzel, H.Ö. (2002). Eğitimde Yeni Bir Yönem ve Disiplin: Yaratici Drama. Yaratici Drama 1985-1995 Yazlar (Ed: H.Ö. Adrgiizel). Ankara: Natürel Kitap Yayıncilik.

Adigüzel, H.Ö. (1993). Oyun ve yaratıc drama ilişkisi. Yayınlanmamış Yüksek Lisans Tezi. Ankara: Ankara Üniversitesi,

Adıgüzel, H. Ö.(2003). Yarancilık Kuramlart. Cocukta Yaratıctlı ve Drama (Ed.Ali Öztïrk). Eskişehir: Anadolu Üniversitesi Yayınları.

Akkoyunlu, B. (1994). Bilgisayarların öğretim programlarındaki yeri ve öğretmenin rolü. 1. Eğitim Bilimleri Kongresi, Adana: Çukurova Üniversitesi, 28-30 Nisan.

Annarella, L. A. (1999). Using creative drama in the witing process. Washington D.C.: Office of Educational Research and Improvement. (ERIC Document Reproduction Service No. ED 434379).

Demirel, Ö. (1996). Türkçe Programı ve Öğretimi. Ankara: Safak Matbaacılık
Dilidüzgün, S.(2002). Çocuk Edebiyatı Karram. Çocuk Edebiyatı (Ed. Zeliha Güneş). Eskişehir: Anadolu Üniversitesi Yayınları.

Floyd, C.T. (1965). English Language Arts in Elemantary School, Florida: State Department of Education.

İpşiroğlu, Z. (1997). Eğitimde Yeni Arayışlar: İstanbul: Adam Yayınlar1.

Kavcar, C., Oğuzkan, F., Sever, S. (1995). Tïkçe Ögretimi. Ankara: Engin Yayınevi.

Onar, G. (2003). Yine Yazt Yaztyoruz (2. Baskt) Ankara: Pegem Yayıncilik.

Özdemir, E. (1994). Yazmsal Tïrler: Ankara: Ümit Yayıncilik.

Rensenbrink, C. 1987. Writing as a play. Language Arts, $64(6), 59-60$.

San, 1. (1985). Sanat ve Yaratıctlık Eğitimi Olarak Tiyatro. (2002) Yarahci Drama (I9S5 - 1995 yazilar (Ed Adigïzel), H.Ö. Ankara: Natürel Yayıncilik.

San, İ. (1996). Yaratta Eğitim lçin Gerekli Yenilikler: Bir Sanat Eğitim Bilimci Gözüyle. Eğitimimize Bakışlar: Ístanbul: Kültür Koleji Eğitim Vakfı Yayınları 1: 179200.

San, İ. (2002).Yaratıcı Drama- Eğitsel Boyutlart. Yaratıcı Drama 1985-1995 Yazlar: (Ed.) H. Ö. Adıgüzel. Ankara: Natürel Kitap Yayıncilı.

Tezcan, M. (1987). Eğitim Sosyolojisi. A. Hakan (Ed.), Eskişehir: Açıöğgretim Fakültesi Yayınları.

Üstündağ, T. (1995). Temel eğitimde drama. Eğitim ve Bilim, $19(95)$.

Üstündağ, T. (200 I). Yaratıcı Drama Öğretmenimin Gïnlï̆g̈i (2. Baski). Ankara: Pegem Yayıncilık. 


\title{
Summary \\ Creative Writing During the Period of Creative Drama
}

\author{
Mijjdat ATAMAN* \\ Bilkent University
}

\section{Introduction}

The explosion of developments in science and technology and knowledge leads us to call our age as science and technology age. These improvements and changes affect also social, economical and political developments. This situation has an effect on people and society and as a result it reveals new life styles (Akkoyunlu, 1994). However, industrialization or being a developed society doesn't mean that we only assimilate technical and economical phenomenon. The main thing is, we should be productive in every aspect in life, we should be creative, and we should reach new thinking styles and grow creative individuals. (San, 1996)

In Turkey, schools are still criticized in terms of being authoritarian, preferring cognitive improvement rather that social improvement, restricting students' social activities and diminishing the creativity of students. (Tezcan, 1987)

Writing isn't seen as a charming activity by children. One of the reasons for that are the strict obligations that they have to follow during writing. In primary years, teaching order of the paper, rules of how to draw a letter, clear writing and grammar make students learn writing techniques but on the other hand they place students' attention on the appearance of writing rather than on its content (Onar, 2003).
Creativity is to establish relations which had not been related before, in this way producing a new experience, idea, life and products in new thinking schemata. Creativity is to reorganize our world of meaning, to add novelty, which is appropriate to reality for individuals or culture. For being creative, first of all one should have selfconfidence, have basic knowledge in his/her study area, think freely and have an environment where s/he can show all his/her talents. (San, 1985)

Creative people discover how unlimited their own worlds are, even if the conditions outside are very coercive. Everyone has creativity potential. This potential differs from individual to individual according to degree and feature. Some have more, some have less, and some use their creativity in science and others in philosophy. The important point is to know every one has more or less creative potential. This potential waits to be discovered and evaluated by the owner. When we realize our creativity then the production period will start. (Onar, 2003)

Creative drama is to animate an idea, an event, a life, a concrete concept or behavior by reorganizing previous cognitive patterns through acting, role playing, theater or other techniques (San, 2002). 
In the education system, to create student-centered classrooms, creative drama is an important method and discipline, which enhance students' creativity. (Adıgüzel, 2003)

İpşiroğlu (1997) found that students who attended creative drama workshops are more interested and successful when compared with students who are educated by classical methods.

Language and thinking can be improved via creative drama. Wagner, who searches the effects of creative drama on learning, concluded that this technique improves not only language development but also self- confidence, self-conscious, empathy, charity, cooperation and other cognitive and emotional traits.

In one of his studies, Stabler stated the goals of language development as an important consequence of creative drama in education.

These goals are:

1- Improvement of self-confident in speaking

2- Improvement of fluency

3- Improvement of speaking

4- Improvement in vocabulary.

5- Improvement in expression of ideas and emotions

6- Improvement in communication

7- Improvement in listening

8- Using different languages in different situations

9- Discussion, differentiation and evaluation talents (Nixon, 1987) (Adigüzel, 1993).

Writing is a concrete expression of thinking. It facilitates sharing of thought and sense and also, writing is the memory of humankind. Like listening and talking, there is also a functional similarity between reading and writing (Özdemir, 1994).

Literature is the writing of an individual's own thinking, living, hearing and seeing.

Resenbrink (1987) suggests some activities which help children to keep their natural desire for writing. The most enjoyable part of fictional writing is to create invisible friends in different characters. On the other hand, readers can find these characters as unrealistic and one dimensional.

In creative writing we can get help from poems and stories. We can change the beginning, middle and the end of stories according to our wishes, we can create new stories by combining several stories, moreover we can even create absolutely different stories. Playing, writing or changing all of the stories and poems enhances children's vocabulary, talent for dreaming and imagination.

Language includes listening, speaking reading and writing. It is necessary to remember writing is a way of communication and a process. Teaching writing via creative drama is an instrument that combines these four forms of communication.

\section{Research Method and Tools}

In this study, the word "suitcase" is chosen. The reason why the word suitcase is chosen is that the word itself is concrete and all students are familiar with it. It is assumed that the word is connotative.

There are 14 students (10 girls, 10 boys- 9,10 years old). The contributors are from BUPS. Up to the 4th grade these students have taken creative drama courses which lasted 40 minutes once every two weeks. These took place in 7 sessions in total, each of which took 75 minutes, between 14:45-16:00, in 21.09.2004-09.11.2004.

The stages of creative drama applications:

1-Warm-up

2- Animation

3- Evaluation

\section{Findings}

In the first week, students were supposed to find words and use them in order to write poems during the sculpture study. In the evaluation form, which was given at the end of the study, there were 70 faces with different feelings. It has been 
discovered that 4 students signed anxiety $(28.5$ $\%), 4$ students signed excitement $(28.5 \%), 2$ students signed joy (14.3\%), 2 students signed happiness (14.3\%), 1 student signed anxiety (7.2\%).

In the second week, they were expected to do story telling using the words that had been found via the connotation of "suitcase". Students found these words in the study of "photograph moment". And then used these words in their stories. They wrote a story titled "suitcase". Seven students $(50 \%)$ wanted to write a story. Four of them did not comment about writing a story. Three of them did not want to write a story. Students did story telling using the words that had been found by connotations.

In the third week, students were expected to write a story about the given title. They were given a questionnaire after the study. Ten of the students stated that they did not have any difficulty in writing a story about the given title, and the same number of the students expressed that they were willing to write a story.

In the fourth week, in the process of creative drama, fairytales were used. Students were asked to complete the missing part of a story. Students picked any objects they liked and they were asked to make a dramatization by using them.

In the fifth week of the study, students wrote a story referring to the given photograph. At the end of the story writing process, students made an evaluation of story by drawing cartoons. When the cartoons were analyzed, it was seen that students were willing to write.

In the sixth week, they were asked to compose a narration, and dramatize it and write it after the dramatization. They composed a horror story by adding sentences to a given one. In this period, students listened and watched their friends carefully and they completed their own stories by concentrating on the task. They dramatized their new stories. At the end of these acting's, they were asked what kind of story they would like to create. All of the students stated that they wanted to write a horror story. At the end of the story all of the students wrote a horror story.
At the last week of the study, they were expected to use imagination while creative writing. They made descriptive sentences referring to the given photograph. The groups acted out by using the photograph. At the end of the dramatizations they used their imagination individually and wrote a story about that photograph.

\section{Discussion}

In Turkey, schools are still criticized in terms of being authoritarian, preferring cognitive improvement rather that social improvement, restricting students' social activities and diminishing the creativity of students (Tezcan, 1987).

Since education is given in traditional methods, it is difficult for the individual to perceive the environment he lives in. For this reason, it is important to use the methods which lead students critical thinking and creativity.

Writing is a process of expressing feelings and thoughts. Usually, children and adults keep away from the action of writing. Although writing objectives in Turkish Primary Curriculum makes writing compulsory, it prevents creative writing. Starting from the second grade the writing process is thought of as consisting of only three stages: introduction, development and conclusion. This continues up to the 12 th grade. And the way of instruction, which repeats itself every year, is also wrong. As a result, students cannot improve their writing skills. Our assessments methods focus on the result rather than the process due to examination anxiety. Most of our assessment methods are based on multiple choice exam questions. This system only improves their comprehension skills rather than writing skills. Students who are educated in this system are observed to get bored easily and therefore fail as their write.

In this study, we provide an environment where they can write creatively, leaving the traditional methods behind. The students' products show that the expected objectives are achieved and students are willing to write.

This study is only an example for creative writing studies. Other methods of creative writing can be used in the creative drama process. 


\section{Conclusion and Suggestions}

Every child has his/her own imagination. During playing, the child identifies the imaginary world with the tools of reality. Since most schools neglect the importance of play in their teaching methods, schools become boring for the child. In this study, it is observed that through this drama activity, children are highly motivated and willing to write.

One of the greatest difficulties of writing is to find a topic to write about. There are a lot of students who complain that there isn't anything interesting for them to write about. In order to solve this problem, teachers could suggest ways to motivate them to improve their imagination.

If we can make them aware of their imagination, most probably they will be able to write willingly. The best way to work this out is to use creative drama. During this study which took 7 weeks the word "suitcase" had been the starting point in the process of their writing. This study can be also applied to Turkish lessons improving the subject and the structure of the lessons.

Students have evaluated each others' works which took their attention more than their teachers' evaluation. Most of the teachers think that evaluation in creative writing is impossible, and this think that it is unfair. Glazer (1994) expects these worries but he also believes that the evaluation could be practical, useful and fair. This evaluation provides teachers specific rubric criteria. The criteria should be based on narration, punctuation and organization skills. These criteria can be altered according to students' capabilities.

In this study, students creativity is considered, it is seen that in their written production there are creative ideas. Teachers can evaluate these works with different criteria. As a result of similar study, one of the student's works (Naz Akyol) was. awarded by Garanti Bank and Turkish Cinema Writers Association. Naz Akyol's work was successful in a competition called "The Movie Scenario in My Dream" which was organized by Garanti Bank and Turkish Cinema Writers
Association. This student's work was published in a book with the other honored competitors.

In 2005, there have been radical improvements in our Primary Curriculum. It is pleasing to see the application of constructivist methods in our program. On the other hand, it is also observed there is still some missing points in terms of Turkish Lesson objectives. In the new program, creative writing studies should be intensifying. Rubric criteria are not explained enough. Although preparatory activities in writing are satisfactory, the motivation activities during the studies are insufficient.

Only through the feedback taken from teachers we can evaluate the objectives and adopt them according to constructivist approach. In this study, as a result, it is seen that students can willingly write only if they are interested in the topic. Therefore MEB should provide an opportunity for the students to write about themselves and their lives.

Teachers should have an opportunity to get familiar with the creative drama area. MEB can get together with the related departments of the universities to form a commission. This commission can present creative drama and creative writing studies in in-service training.

Students should share their works not only with their teachers but also with their classmates.

Individual differences should be taken into consideration during their evaluation. For this way of assessment, self-evaluation rubrics can be prepared. It is also good for students to learn how to make self- evaluation.

It shouldn't be forgotten that writing is a process and it shouldn't be expected that students' first products have a literary value.

In order for them to write a product that has literary value, students should read books, stories, poems that have literary value. Teacher should also follow new products of children literature. Teachers should also use photographs, pictures, films and music which have artistic value as their teaching materials. 
